\title{
Insulin and Glucagon Release in the Diabetic Chinese Hamster: Differences Among Inbred Sublines
}

\author{
B.J. Frankel ${ }^{1, *}$, A. M. Heldt ${ }^{1}$ and G. M. Grodsky ${ }^{1,2}$ \\ ${ }^{1}$ Metabolic Research Unit, and 2Department of Biochemistry and Biophysics, University of California, San Francisco, California, USA
}

\begin{abstract}
Summary. Release of insulin and glucagon from perfused pancreases in vitro of 40 normal male and female Chinese hamsters (from one inbred subline) and 110 male and female diabetic hamsters (from three inbred sublines) was measured in response to glucose plus arginine, theophylline alone, or potassium alone, in order to determine if differences in hormone secretion exist among different diabetic sublines. Glucose plus arginine and potassium produced subnormal insulin responses in all three diabetic sublines, whereas theophylline induced 'normal' or above normal insulin responses. Excessive glucagon release was consistently seen in only one diabetic subline. The female normal animals showed greater insulin release than the male normal hamsters in response to glucose plus arginine. This sex difference was not seen in the diabetic animals.
\end{abstract}

Key words: Chinese hamster, diabetes model, glucagon excess, glucagon release, insulin deficiency, insulin release, potassium, insulin secretion, theophylline.

Certain inbred sublines of Chinese hamsters (Cricetulus griseus) spontaneously develop an insulin-deficient, non-obese type of diabetes mellitus with many sequelae similar to those seen in human diabetes [1,2]. Previous studies $[3,4]$ have shown that the perfused pancreases of diabetic hamsters have subnormal insulin and excessive glucagon responses to glucose stimulation, excessive glucagon responses to arginine, but normal responses to theophylline. However, those studies did not compare the differences among specific diabetic sublines nor between males and females.

\footnotetext{
* Present address: Department of Histology and Cell Biology, University of Umeå, Sweden
}

In the last few years, several sublines have become more highly inbred, and differences in pancreatic and plasma levels of insulin and glucagon among different diabetic sublines have been observed [1, personal communication G.C.Gerritsen, Upjohn, Kalamazoo, Michigan, USA]. No morphological or biochemical studies which might explain the differences in pancreatic and plasma hormones among diabetic sublines have been published. Therefore, to characterize the defect(s) in pancreatic hormone secretion in the diabetic hamster, the effects of three different secretagogues were studied on insulin and glucagon release from the perfused pancreases of hamsters from one inbred normal and three different inbred diabetic sublines. The stimuli were as follows: a combination of glucose (low concentration) plus arginine, theophylline alone, and potassium alone. These particular secretagogues were chosen because they stimulate both insulin and glucagon release and because each is believed to induce insulin release by a different, though related mechanism, i.e. through metabolism, elevation of intracellular cyclic AMP and calcium, and membrane depolarization, respectively.

\section{Materials and Methods}

Adult Chinese hamsters from one inbred normal (M) and three inbred diabetic (L, X, and Z) sublines were obtained from the Chinese Hamster Program Project colony at Kalamazoo, Michigan, USA [5]. It appears that these three diabetic sublines have subnormal pancreatic insulin, low and variable plasma insulin, and subline $L$ has an excessive pancreatic glucagon level (G.C. Gerritsen, personal communication). None of the individual diabetics studied had shown more than an occasional positive test for ketonuria. Blood was drawn from the orbital sinus [6] and plasma glucose levels were determined with a Beckman glucose analyzer. The mean \pm SEM fed plasma glucose level (usually collected between 1030 and $1100 \mathrm{~h})$ was $5.4 \pm 0.2 \mathrm{mmol} / \mathrm{l}(n=32)$ in the normal and $17.8 \pm 0.5 \mathrm{mmol} / 1(n=106)$ in the diabetic hamsters. 


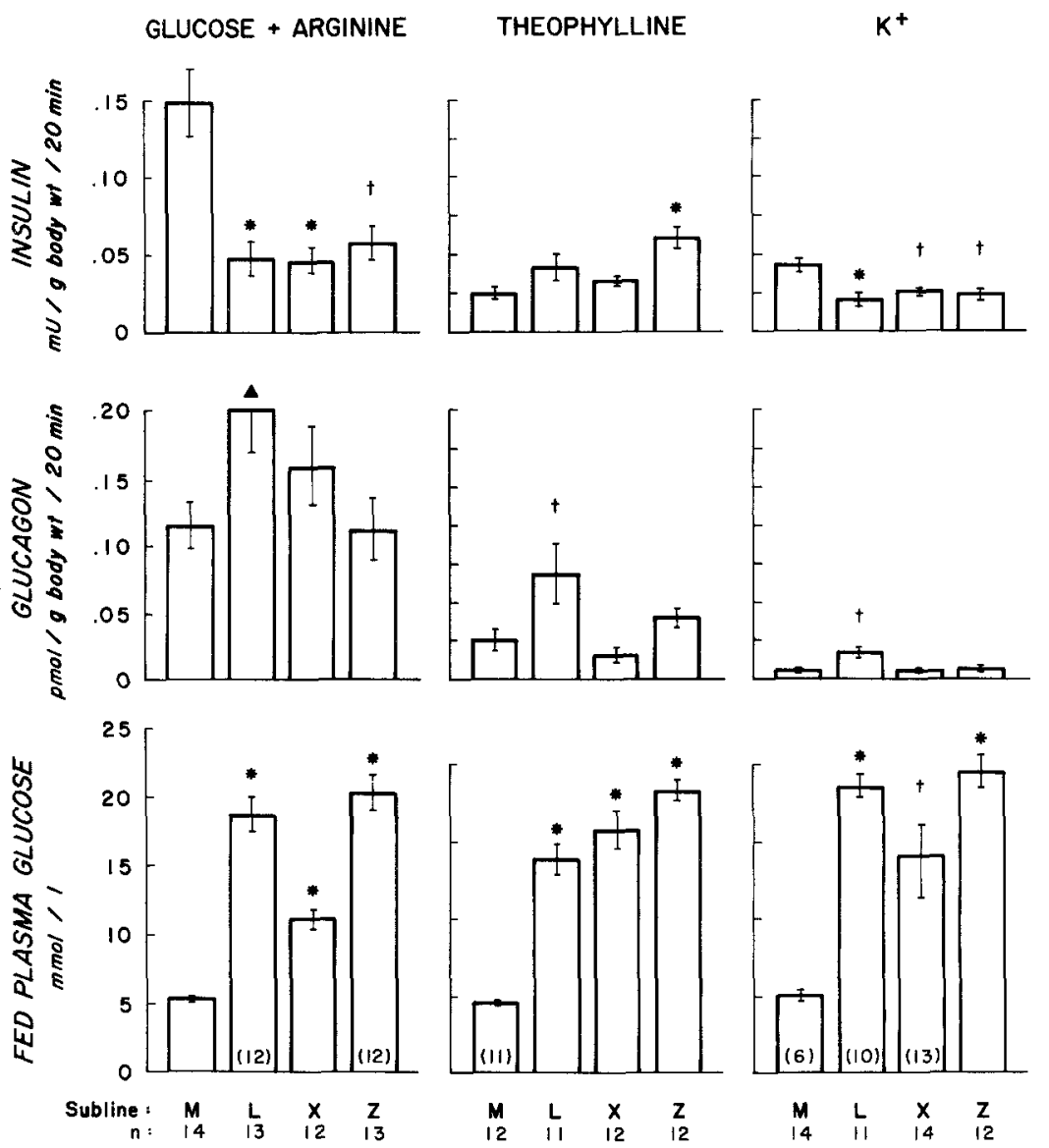

Fig. 1. Mean hormone release and plasma glucose levels in response to glucose $(5.6 \mathrm{mmol} / \mathrm{l})$ plus arginine $(20 \mathrm{mmol} / \mathrm{l})$, theophylline $(10 \mathrm{mmol} / \mathrm{l})$, or potassium $\left(\mathrm{K}^{+}\right)(18.3 \mathrm{mmol} / \mathrm{l})$ from normal (subline $\mathrm{M}$ ) or diabetic (sublines $\mathrm{L}, \mathrm{X}$, and $\mathrm{Z}$ ) hamsters. Hormone release $( \pm S E M)$ is expressed per g body weight per $20 \mathrm{~min}$. Numbers in parentheses indicate number of animals in which plasma glucose was measured when less than the number of pancreases perfused (n). The twotailed Student's t test was used to compare each diabetic subline to the normal subline. ${ }^{*} p<0.001 ; \dagger p<0.005$ $\Delta p<0.025$
Pancreatic perfusion was performed in vitro as described previously $[3,4]$ except that the total perfusion flow rate was only $1.3 \mathrm{ml} /$ min, the animals were not fasted before perfusion, and glucagon was assayed using Unger $30 \mathrm{~K}$ or $04 \mathrm{~A}$ antiserum. These two antisera gave identical results in our assays of glucagon release from normal rat pancreas in vitro. Glucose plus arginine and the $\mathrm{KCl}$ were injected by sidearm syringe into the perfusion buffer at $0.05 \mathrm{ml} / \mathrm{min}$, whereas the theophylline (due to its relative insolubility) was dissolved directly in the perfusate in one of two reservoirs. Total insulin and glucagon release during $20 \mathrm{~min}$ perfusion periods with the different stimuli were calculated from the corresponding time curves. A declining basal glucagon secretion was subtracted.

\section{Results}

In the normal hamsters, glucose plus arginine caused biphasic patterns of insulin and glucagon release (insulin second phase constant, glucagon second phase falling), whereas theophylline gave essentially constant second phase insulin and glucagon release $[3,7]$. Potassium caused rapid release of insulin and glucagon in the first phases, with little insulin and no glucagon in the second phases [7]. The mean insulin and glucagon responses from the four different sublines (normal $\mathrm{M}$, and diabetic $\mathrm{L}, \mathrm{X}$, and $\mathrm{Z}$ ) and the plasma glucose levels are shown in Figure 1.
In response to glucose plus arginine, and to potassium, all three diabetic sublines showed significantly less insulin release than the normal animals, but only the diabetic L subline showed significantly greater glucagon release than normal. In response to theophylline, only the diabetic $\mathrm{Z}$ subline showed total insulin significantly greater than normal and again, only the diabetic hamsters in subline L showed significantly greater than normal glucagon release.

Although the L-subline hamsters consistently showed greater glucagon release than the normal and other diabetic sublines, the $\mathrm{L}$ subline did not have a significantly greater mean plasma glucose level than the diabetic sublines $X$ and $Z$. Also, there was no obvious correlation among the diabetic sublines between the mean insulin release and the mean plasma glucose level.

An unexplained sex difference was noted in the insulin responses to glucose plus arginine (Table 1). The normal female hamsters released nearly twice as much insulin as their male siblings $(p<0.02)$. In contrast, the diabetic females in each subline tended to release less insulin than their male counterparts, although this difference was only statistically significant in one of the diabetic sublines $(Z)$. The diabetic 
Table 1. Insulin release in response to glucose plus arginine and plasma glucose in female and male chinese hamsters

\begin{tabular}{|c|c|c|c|c|c|c|c|}
\hline \multirow{2}{*}{\multicolumn{2}{|c|}{$\begin{array}{l}\text { Condition } \\
\text { and Subline }\end{array}$}} & \multicolumn{3}{|c|}{ Insulin release ( $\mu \mathrm{U} / \mathrm{g}$ body weight per $20 \mathrm{~min})$} & \multicolumn{3}{|c|}{ Plasma glucose (mmol/1) } \\
\hline & & \multirow{2}{*}{$\begin{array}{l}\text { Females } \\
197.5 \pm 27.5(7)\end{array}$} & \multirow{2}{*}{$\begin{array}{l}\text { Males } \\
100.0 \pm 22.5(7)\end{array}$} & \multirow{2}{*}{$\frac{p}{<0.02}$} & \multirow{2}{*}{$\frac{\text { Females }}{5.3 \pm 0.1(7)}$} & \multirow{2}{*}{$\frac{\text { Males }}{5.6 \pm 0.2(7)}$} & \multirow{2}{*}{$\frac{\mathrm{p}}{\mathrm{NS}}$} \\
\hline Normal & $-\mathrm{M}$ & & & & & & \\
\hline Diabetic & $-\mathrm{L}$ & $30.0 \pm 7.5(6)$ & $62.5 \pm 17.5(7)$ & NS & $19.4 \pm 2.7(5)$ & $18.2 \pm 1.1(7)$ & NS \\
\hline Diabetic & $-\mathrm{X}$ & $30.0 \pm 10.0(6)$ & $62.5 \pm 10.0(6)$ & NS & $12.6 \pm 0.7(6)$ & $9.8 \pm 1.6(6)$ & $<0.02$ \\
\hline Diabetic & $-\mathrm{Z}$ & $37.5 \pm 7.5(7)$ & $80.0 \pm 17.5(6)$ & $<0.05$ & $22.6 \pm 2.0(6)$ & $17.9 \pm 0.8(6)$ & NS \\
\hline
\end{tabular}

Data given as mean \pm SEM with number of animals in parentheses. Statistical significance determined by two-tailed Student's $t$ test. NS $=$ not significant.

females' lower insulin release was not correlated with a higher mean plasma glucose level. No significant sex difference was seen in the normal hamsters' insulin responses to theophylline or potassium or in any of the glucagon responses.

\section{Discussion}

The present study shows that there are significant differences in the stimulated pancreatic hormone secretion among the inbred sublines of diabetic hamsters. Subnormal insulin release was common to all three sublines studied, but excessive glucagon release was observed only in one. Unfortunately, we cannot compare these data with the levels of pancreatic hormone in the individual animals studied. However, Gerritsen $[1$, personal communication] has noted significantly subnormal pancreatic and plasma insulin levels in sublines $X$ and $Z$ and supranormal pancreatic and plasma glucagon levels in subline $\mathrm{L}$. Therefore, it appears that inbreeding has produced both 'normal glucagon' ( $\mathrm{X}$ and $\mathrm{Z}$ ) and 'hyperglucagon' forms of diabetes in the Chinese hamster, and that pancreatic release in vitro may roughly parallel pancreatic content.

The secretagogues used in this study were chosen on the basis of their abilities to induce insulin and glucagon release and their presumed mechanisms of action. Glucose plus arginine causes metabolic events affecting glycolysis, the Krebs' cycle, ATP, hydrogen ion concentration, NADPH, membrane depolarization and changes in membrane fluxes of calcium in the B cell [8]. Theophylline presumably elevates cyclic AMP and changes intracellular calcium ion levels, while potassium acts more distally on membrane polarization.

The diabetics' subnormal insulin responses to glucose plus arginine and to potassium could be due to subnormal islet insulin synthesis [9] and content [3, 10, Gerritsen, personal communication]. However, because theophylline caused normal or greater than normal insulin release, the effectiveness of cyclic
AMP and the process of exocytosis appear to be nor$\mathrm{mal}$, and thus insulin release, at least in response to theophylline, appears to be unrelated to pancreatic content. Alternatively, the excess glycogen seen in the diabetic B cell $[11,12]$ may act as an intracellular source of glucose intermediates, and these metabolites may act synergistically with theophylline [3] to promote insulin release in the diabetic.

The diabetic B cell in the Chinese hamster and in man may fail to recognize specific insulin secretagogues. For example, some diabetic patients show subnormal early insulin responses to glucose but normal responses to tolbutamide [13], glucagon [14], arginine [15] and isoproterenol [16]. A glucose-specific defect may exist in the diabetic hamster since glucose fails to induce normal insulin synthesis [9], cyclic AMP production [17], calcium efflux [18] and insulin release [3, 9, 17-19].

Because diabetic hamster islets show little calcium efflux during stimulation with glucose plus the phosphodiesterase inhibitor 3-isobutyl-1-methylxanthine [18], there may be an improper storage of calcium within the diabetic hamster $\mathrm{B}$ cell such that glucose [18] or potassium-induced depolarization (the present study) is not able to provide sufficient intracellular calcium for exocytosis.

The mean plasma glucose level in each diabetic subline, or in the male and female diabetics separately, did not clearly correlate with the subnormal insulin and normal or excessive glucagon release, thus nonpancreatic abnormalities may contribute to the hyperglycaemia in Chinese hamsters. Hyperphagia is found in some prediabetic hamsters and diet is an important factor [20]. Also, peripheral insulin resistance is suggested under some circumstances, since exogenous insulin has been shown to exacerbate diabetes in hamsters [21], possibly by inducing mild weight gain and decreased insulin receptor function [22].

In response to glucose plus arginine, the normal females showed a significantly higher mean insulin response than the normal males, whereas in the diabetics, the females tended to show lower insulin re- 
sponses than the males. However, only in the diabetic $\mathrm{Z}$ subline was this latter difference statistically significant. No sex difference was seen in the insulin responses to theophylline or potassium or in any of the glucagon responses. No clear sex difference was seen in an earlier study in the insulin responses to glucose alone [3]. These data do not explain the cause of the sex difference but suggest that it may be reversed in diabetics and that it is secretagogue- and possibly subline-specific.

In conclusion, the diabetic Chinese hamster is a useful model for the study of diabetes because the disease duplicates many of the abnormalities and complications seen in human diabetes [1]. In this investigation decreased insulin responses to glucose plus arginine and to potassium were seen consistently in all three diabetic sublines, whereas excessive glucagon release was seen only in one. Therefore, different 'types' of diabetes exist among the different sublines of diabetic Chinese hamsters, and excess glucagon release does not accompany all forms of insulin deficiency in these animals. Theophylline caused greater than normal insulin release in some of the diabetics, suggesting that specific secretagogues, rather than the pancreatic content, determine insulin release. Defects in pancreatic hormone synthesis, the ability of specific secretagogues to induce release (stimulus-secretion coupling), islet calcium ion handling, and peripheral factors (hyperphagia, resistance) may all contribute to the diabetes in the Chinese hamster.

Acknowledgements. We are indebted to R. Fanska, M.Gishizky, M. A.Jones, and M. Manning for their technical assistance, and to Dr. F. Matschinsky for his advice in the preparation of this manuscript. This work was supported in part by NIH grants AM 26033 , AM 21933 and by AM 01410. Grant AM 21933 provided the animals from the Chinese Hamster Program Project colony. BJF is a recipient of a New Investigator Research Award in Diabetes from the National Institute of Arthritis, Metabolism and Digestive Diseases.

\section{References}

1. Dulin WE, Gerritsen GC, Chang AY (1982) Experimental and spontaneous diabetes in animals. In: Ellenberg $M$, Rifkin $\mathbf{H}$ (eds) Diabetes mellitus: theory and practice, third ed. Medical Examination Publishing Co., Garden City, New York (in press).

2. Gerritsen GC, Blanks MC, Schmidt FL, Dulin WE (1976) Environmental influences on the manifestation of diabetes mellitus in Chinese hamsters. In: Creutzfeldt W, Kobberling J, Neel JV (eds) The genetics of diabetes mellitus. Springer, Berlin Heidelberg New York pp 165-187

3. Frankel BJ, Gerich JE, Hagura R, Fanska RE, Gerritsen GC, Grodsky GM (1974) Abnormal secretion of insulin and glucagon by the in vitro perfused pancreas of the genetically diabetic Chinese hamster. J Clin Invest 53: 1637-1646
4. Frankel BJ, Gerich JE, Fanska RE, Gerritsen GC, Grodsky GM (1975) Responses to arginine of the perfused pancreas of the genetically diabetic Chinese hamster. Diabetes 24: 272-279

5. Gerritsen GC, Dulin WE (1967) Characterization of diabetes in the Chinese hamster. Diabetologia 3:74-84

6. Riley V (1960) Adaptation of orbital bleeding technique to rapid serial blood studies. Proc Soc Exp Biol Med 104: 751-754

7. Grodsky GM, Frankel BJ (1981) Diabetes mellitus in the Chinese hamster. In: Martin JM, Ehrlich RM, Holland FJ (eds) Etiology and pathogenesis of insulin-dependent diabetes mellitus. Advances in pediatric research series. Raven Press, New York, pp 239-249

8. Hedeskov CJ (1980) Mechanism of glucose-induced insulin secretion. Physiol Rev 60: 442-509

9. Chang AY (1970) Insulin synthesis and secretion by isolated islets of spontaneously diabetic Chinese hamsters. In: Falkmer $\mathrm{S}$, Hellman B, Täljedal I-B (eds) The structure and metabolism of the pancreatic islets. Pergamon Press, Oxford, pp 515-526

10. Grodsky GM, Frankel BJ, Gerich JE, Gerritsen GC (1974) The diabetic Chinese hamster: In vitro insulin and glucagon release; the 'chemical diabetic'; and the effect of diet on ketonuria. Diabetologia 10:521-528

11. Williamson JR (1960) Electron microscopy of glycogenic changes in beta cells in experimental diabetes. Diabetes 9: $471-480$

12. Luse SA, Caramia F, Gerritsen G, Dulin WE (1967) Spontaneous diabetes mellitus in the Chinese hamster: An electron microscopic study of the islets of Langerhans. Diabetologia 3: 97-108

13. Varsano-Aharon N, Echemendia E, Yalow RS, Berson SA (1970) Early insulin response to glucose and to tolbutamide in maturity-onset diabetes. Metabolism 19: 409-417

14. Simpson RG, Benedetti A, Grodsky GM, Karam JH, Forsham PH (1968) Early phase of insulin release. Diabetes 1:684-692

15. Palmer JP, Benson JW, Walter RM, Ensinck JW (1976) Arginine-stimulated acute phase of insulin and glucagon secretion in diabetic subjects. J Clin Invest 58:565-570

16. Robertson RP, Porte D Jr (1973) The glucose receptor. A defective mechanism in diabetes mellitus distinct from the beta adrenergic receptor. J Clin Invest 52:870-876

17. Rabinovitch A, Renold AE, Cerasi E (1976) Decreased cyclic AMP and insulin responses to glucose in pancreatic islets of diabetic Chinese hamsters. Diabetologia 12:581-587

18. Siegel EG, Wollheim CB, Sharp GWG, Herberg L, Renold AE (1979) Defective calcium handling and insulin release in islets from diabetic Chinese hamsters. Biochem J 180: 233-236

19. Malaisse W, Malaisse-Lagae F, Gerritsen GC, Dulin WE, Wright PH (1967) Insulin secretion in vitro by the pancreas of the Chinese hamster. Diabetologia 3:109-114

20. Gerritsen GC, Blanks MC, Miller RL, Dulin WE (1974) Effect of diet limitation in the development of diabetes in prediabetic Chinese hamsters. Diabetologia 10:559-566

21. Frankel BJ, Grodsky GM (1979) Effect of continuous low-dose insulin treatment on subsequent incidence of diabetes in genetically prediabetic Chinese hamsters. Diabetes 28 : 544-547

22. Loten EG, Le Marchand Y, Assimacopoulos-Jeannet F, Denton RM, Jeanrenaud B (1976) Does hyperinsulinemia in ob/ob mice cause an insulin-stimulated adipose tissue? Amer J Physiol 230: 602-607

Received: 3 August 1981

and in revised form: 29 November 1981

Dr. B.J. Frankel

Departement of Histology and Cell Biology

University of Umeå

S-901 87 Umeå, Sweden 